\title{
FREE WILL, DE SAM HARRIS
}

\author{
Gabriel Garmendia da Trindade* \\ University of Birmingham \\ https://orcid.org/0000-0001-7140-991X
}

\section{HARRIS, Sam. Free Will. New York: Free Press, 2012.}

Os seres humanos são realmente livres? O problema do livre-arbítrio não somente tem fascinado pensadores de todos os períodos da tradição filosófica ocidental ${ }^{1}$, mas também intelectuais das mais variadas áreas do conhecimento (Direito, teologia, psicologia, física quântica, teoria dos jogos, etc.). A despeito de profunda e vasta problematização durante séculos, não há qualquer sinal de consenso entre os especialistas acerca da questão do livre-arbítrio ${ }^{2}$. Em Free Will, o neurocientista e escritor popular Sam Harris ${ }^{3}$ dá novo fôlego a essa discussão ao expor e defender uma das posições mais controversas, porém instigantes desse debate, qual seja: o livre-arbítrio é uma ilusão.

Um dos objetivos centrais de Harris em seu livro é contestar a concepção coloquial de livre-arbítrio. Tal concepção estaria fundamentada em duas suposições: "(1) cada um de nós poderia ter agido de modo diferente do que agimos no passado, e (2) nós somos a fonte consciente da maioria de nossas ações e pensamentos no presente" (HARRIS, 2012, p. 6) ${ }^{4}$. Segundo ele, todavia, ambas as suposições são falsas. Elas são problemáticas, pois, em realidade, "nós estamos conscientes de apenas uma

\footnotetext{
* Doutorando em Global Ethics no Centre for the Study of Global Ethics, Department of Philosophy, University of Birmingham. Bolsista CAPES/UoB. E-mail: garmendia_gabriel@hotmail.com ougxg322@bham.ac.uk

1 Para um excelente exame histórico-filosófico do problema do livre-arbítrio, veja: DILMAN, Ilham. Free will: an historical and philosophical introduction. Oxon: Routledge, 1999.

${ }^{2}$ Como ressaltam Mele, Vohs \& Baumeister, não há nem mesmo acordo sobre como a própria noção de livre-arbítrio deveria ser compreendida (2010, p. 2). MELE, Alfred R.; VOHS, Kathleen D.; BAUMESTEIR, Roy F. Free will and consciousness: an introduction and overview of perspectives. In: (eds.) Free will and consciousness: how might they work? New York: Oxford University Press, 2010. p. 1-8.

${ }^{3}$ Entre as principais obras de Harris, destacam-se: Carta a uma nação cristã (2007), A morte da fé: religião, terror e o futuro da razão, A paisagem moral: como a ciência pode determinar os valores humanos (2013), Despertar: um guia para a espiritualidade sem religião (2015) - todas publicadas no Brasil pela editora Companhia das Letras.

${ }^{4}$ Todas as traduções presentes nessa resenha foram realizadas livremente pelo autor.
} 
pequena fração da informação que nossos cérebros processam a cada momento" (HARRIS, 2012, p. 7). Deveras, ainda que humanos sejam capazes de perceber mudanças e nuances em experiências pessoais - e.g., alterações de humor e comportamento, trocas repentinas de pensamento, etc. -, em última análise, "nós estamos completamente alheios aos eventos neurofisiológicos que as produzem" (HARRIS, 2012, p. 7).

Com base em diversos estudos científicos ${ }^{5}$, Harris relata que momentos antes de alguém estar ciente de qual será a sua próxima ação, o cérebro da pessoa em questão já determinou (às vezes, até mesmo com vários segundos de antecedência) o que será feito a seguir. Esse indivíduo, então, torna-se ciente da "escolha" e prontamente crê que ela é o resultado direto de uma decisão consciente tomada por ele. Em outras palavras, há um atraso entre os eventos neurofisiológicos que estimulam o próximo pensamento consciente que alguém terá e o pensamento em si mesmo. O que se segue é a crença (ilusória) de que o agente é o autor consciente de suas decisões e atos. Além disso, a própria intenção de decidir por algo entre um grupo de opções distintas não se origina na consciência. Tal intenção, assim como outros pensamentos e impulsos contrários a ela, apenas "surgem" na consciência. Como descreve Harris, "atos aparentes de volição meramente emergem de forma espontânea [...] e não podem ser traçados a um ponto de origem em nossas mentes conscientes" (HARRIS, 2012, p. 6). Os resultados dos experimentos abordados por Harris claramente contradizem as duas suposições que constituem a concepção popular de livre-arbítrio. Por conseguinte, sustenta Harris, o melhor a se fazer é abandonar tal concepção.

Uma vez explorada a interpretação coloquial da noção de livrearbítrio, Harris dá início a uma rápida análise das três principais teorias filosóficas dedicadas ao problema do livre-arbítrio, a saber: determinismo, libertarismo e compatibilismo. Deterministas e libertaristas afirmam que se as ações e pensamentos humanos forem, de fato, determinados por um conjunto de causas antecedentes, então o livre-arbítrio é uma ilusão. Por sua vez, compatibilistas mantêm que a tese de que o comportamento humano é determinado por relações de causalidade não exclui, necessariamente, a

\footnotetext{
${ }^{5}$ As pesquisas a que Harris se refere são: LIBET, Benjamin. et al. Time of conscious intention to act in relation to onset of cerebral activity (readiness-potential). The unconscious initiation of a freely voluntary act. Brain, n. 106 (Pt 3), p. 623-642, Sep. 1983. LIBET, Benjamin. Unconscious cerebral initiative and the role of conscious will in voluntary action. Behavioral and Brain Sciences, v. 8, n. 4, p. 529-566, 1985. BANKS, W. P.; ISHAM, E. A. We infer rather than perceive the moment we decided to act. Psychological Science, v. 20, n. 1, p. 17-21, Jan. 2009. HAYNES, J. D. Decoding and predicting intentions. Annals of the New York Academy of Sciences, v. 1224, n. 1, p. 9-21, Apr. 2011. FRIED, I.; MUKAMEL, R.; KREIMAN, G. Internally generated preactivation of single neurons in human medial frontal cortex predicts volition. Neuron, v. 69, n. 3, p. 548-562, Feb. 2011. HAGGARD, Patrick. Decision time for free will, Neuron, v. 69, n. 3 , p. 404-406, Feb. 2011.
} 
ideia de livre-arbítrio. É preciso notar, todavia, que a compreensão de livrearbítrio articulada por proponentes do compatibilismo diverge bastante da concepção popular comentada acima.

Conforme explica Harris, "compatibilistas comumente argumentam que uma pessoa é livre enquanto ela for livre de quaisquer compulsões externas ou internas que a impeçam de agir segundo seus verdadeiros desejos e intenções" (HARRIS, 2012, p. 16). Tal posição, no entanto, também possui problemas. $\mathrm{O}$ fato é que "a maioria das pessoas é governada por diversas metas e aspirações mutualmente incompatíveis" (HARRIS, 2012, p. 18). Por exemplo, Jack quer terminar o artigo que está escrevendo, porém ele também quer deixar o texto de lado para assistir o novo episódio do seriado de que tanto gosta. John está economizando para fazer uma grande viagem, mas ele está igualmente tentado a comprar um livro caríssimo de sua autora favorita. Como questiona Harris, "onde está a liberdade quando um desses desejos opostos inexplicavelmente triunfa sobre o outro?" (HARRIS, 2012, p. 18-19). Mais importante ainda, "onde está a liberdade em estar perfeitamente satisfeito com seus pensamentos, intenções e ações subsequentes quando eles são o produto de eventos passados sobre os quais você não teve absolutamente nenhum papel na criação?" (HARRIS, 2012, p. 19). Dito isso, conclui Harris, mesmo exponentes do compatibilismo - a principal defesa filosófica do livre-arbítrio hoje em dia enfrentam sérias dificuldades para harmonizar a sua interpretação do que é "ser livre" e a realidade dos incontáveis eventos neurais inconscientes (e suas próprias causas antecedentes) que determinam o comportamento humano.

Outro ponto importante a ser ressaltado diz respeito às implicações práticas da negação do livre-arbítrio humano. Por exemplo, a ideia de livrearbítrio é a pedra angular de múltiplos sistemas jurídico-penais ao redor do mundo. Se o livre-arbítrio é uma simples ilusão, como afirmado por Harris, então o mesmo deve valer para a ideia de responsabilidade moral e outras concepções correspondentes. Noções tais como "bem" ou "mal", "certo" ou "errado" estão intimamente ligadas à capacidade de pensar e agir livremente. Se os pensamentos e atos humanos são apenas o resultado de uma cadeia de causas antecedentes sobre as quais não se tem controle, fica difícil imaginar como alguém poderia ser julgado moral e criminalmente por algo que tenha feito. Harris está ciente disso. No seu entender, para que seja possível preservar a ideia de responsabilidade moral dos seres humanos é preciso repensar tal noção de modo que ela coincida com os fatos atinentes à neurofisiologia humana.

Segundo Harris, “juízos de responsabilidade dependem da compleição geral da mente de alguém, e não da metafísica da causa e efeito mentais" (HARRIS, 2012, p. 49). Nesse sentido, dizer que alguém é responsável pelo seu comportamento significa que as ações dessa pessoa estão em consonância com seus pensamentos, crenças, intenções e desejos, 
sendo, então, uma extensão deles. No intuito de elaborar mais profundamente a sua posição acerca da responsabilidade moral humana, Harris apresenta e discute uma série de casos hipotéticos. Dois dos cenários delineados mostram-se como os mais relevantes:

\begin{abstract}
4. Um homem de 25 anos que foi criado por pais maravilhosos e que nunca sofreu nenhum tipo de abuso atirou e matou intencionalmente uma jovem que ele não conhecia por "pura diversão".

5. Um homem de 25 anos que foi criado por pais maravilhosos e que nunca sofreu nenhum tipo de abuso atirou e matou intencionalmente uma jovem que ele não conhecia por "pura diversão". Um exame de IRM [imagem por ressonância magnética] do cérebro do homem revelou um tumor do tamanho de uma bola de golfe no seu córtex pré-frontal medial (região responsável pelo controle das emoções e impulsos comportamentais). (HARRIS, 2012, p. 50)
\end{abstract}

Em ambos os casos esboçados, uma jovem morre devido às ações de outro indivíduo. Tais ações, por seu turno, são o resultado de uma miríade de eventos que ocorreram no cérebro do assassino. Apesar do desfecho ser idêntico, "o grau de ultraje moral que sentimos depende das condições de fundo descritas em cada caso" (HARRIS, 2012, p. 50-51). Enquanto o homem do 'caso 4' seria rapidamente considerado pela grande maioria das pessoas como um "sociopata", o tumor existente no cérebro do agressor do 'caso 5' faz com que muitos vejam o cenário em questão de maneira diferente. Em outras palavras, embora o motivo torpe e o comportamento homicida exibidos pelo homem do 'caso 5' sejam os mesmos que o do 'caso 4', o tumor em seu cérebro parece eximi-lo de toda a sua responsabilidade pela morte da jovem. Como nota Harris, "a partir do momento em que compreendemos que os seus sentimentos tiveram uma causa física, um tumor cerebral, nós não conseguimos evitar de vê-lo senão como uma vítima de sua própria biologia" (HARRIS, 2012, p. 51).

Porém, por que exatamente a enfermidade do agressor do 'caso 5' faz com que muitos tomem dois cenários com desfechos idênticos como dignos de juízos de responsabilidade dissimilares? Uma possível razão é o fato de que se não fosse pela influência do tumor, pode-se assumir, o homem do 'caso 5' não agiria da forma que o fez. Contudo, quando ambos os cenários são analisados à luz da neurofisiologia humana, o que se percebe é que o agressor do 'caso 5' não é mais responsável pelo tumor em seu cérebro e os pensamentos e atos que se seguem dele do que o assassino do 'caso 4' pelos eventos mentais que o fizeram atacar a sua vítima. Ou seja, "quanto mais compreendemos a mente humana em termos causais, mais difícil se torna de traçar uma distinção entre casos como 4 e 5" (HARRIS, 2012, p. 54). 
Para Harris, é certamente possível reconhecer que alguns indivíduos são perigosos sem que se recorra à ideia de que humanos são os reais autores de seus pensamentos, intenções e ações. Graus de responsabilidade moral e culpabilidade podem ser muito bem determinados com base nos fatos do caso discutido. Por exemplo, "se o acusado aparenta não estar arrependido, mas sim disposto a matar novamente, não precisamos entreter quaisquer noções de livre-arbítrio para considerá-lo um perigo à sociedade" (HARRIS, 2012, p. 52). Conforme observa Harris, a justificativa para encarcerar certos criminosos é bastante direta e simples: o restante da população ficará mais seguro se tais indivíduos forem impedidos de ameaçálo. Ademais, "abandonar a ilusão de livre-arbítrio nos permitirá focar naquilo que importa - avaliar riscos, proteger pessoas inocentes, desencorajar o crime, etc." (HARRIS, 2012, p. 53). O fato é que a despeito do contínuo fomento e defesa de uma concepção de responsabilidade moral fundamentada em um comportamento humano consciente e deliberado, "a maioria de nós sabe que desordens do cérebro podem derrubar as melhores intenções da mente" (HARRIS, 2012, p. 55). Algo que se mostra particularmente claro quando casos como ' 4 ' e ' 5 ' são examinados com a devida atenção. Como conclui Harris, "tal mudança de entendimento representa um progresso em direção a uma visão mais profunda, consistente e compassiva de nossa humanidade partilhada" (HARRIS, 2012, p. 55).

Para finalizar, Free Will é um livro conciso, porém pontual. Harris compromete-se a abordar a questão do livre-arbítrio sob o prisma das últimas descobertas da neurociência, e é exatamente isso o que ele faz. Apesar da clareza de sua escrita e precisão de seus argumentos, todavia, muitos leitores talvez não se sintam completamente convencidos de que não são os verdadeiros autores de seus pensamentos, intenções e ações. Ainda há muito a ser dito em prol do livre-arbítrio humano. De fato, o debate filosófico sobre o problema aqui tratado é bem mais complexo e amplo do que Harris faz parecer. Por essa razão, interessados na temática em pauta deveriam complementar as provocações levantadas em Free Will com a leitura de outras obras e textos relevantes ${ }^{6}$.

\footnotetext{
${ }^{6}$ Uma sugestão de leitura é: KANE, Robert (Ed.). The Oxford Handbook of Free Will. Second Edition. New York: Oxford University Press, 2011. A segunda edição do The Oxford Handbook of Free Will conta com vinte e nove artigos elaborados por alguns dos maiores especialistas da atualidade sobre a questão do livre-arbítrio. As quase setecentas páginas dessa coletânea cobrem todos os tópicos discutidos por Harris em Free Will e muitos outros mais (e.g. a relação entre livre-arbítrio e o sentido da vida; e livre-arbítrio e identidade pessoal).
} 